\title{
Metamaterial Grounded Planar Bilayers Supporting Leaky Waves: Principles and Applications
}

UDK 621.396 .677

IFAC 5.8 .3

Preliminary communication

In this contribution, we review the analysis of metamaterial grounded planar bilayers supporting leaky-waves, which we have recently proposed elsewhere as compact sub-wavelength leaky-wave radiators, and for enhancing the wave transmission through apertures over conducting screens when used as covers. Exploiting the peculiar resonances arising when »complementary« or »conjugate« metamaterials are paired, together with the focusing properties of low-permittivity and/or low-permeability materials, it is possible to operate a sub-wavelength open waveguide consisting of a stack of grounded metamaterial bilayers in the leaky-wave regime. We recall the salient guidance and radiation properties of these anomalous natural modes, providing some physical insights into the phenomenon and speculating on the connections between these two potential applications.

Key words: metamaterials, leaky-waves

\section{INTRODUCTION}

The use of engineered artificial metamaterials has been proposed in the last few years for several applications at microwaves and higher frequencies, mainly due to the novel possibility of synthesizing materials with low or negative permittivities and/or permeabilities by properly inserting small metallic or dielectric inclusions in a host material [1-4]. Such media have been thoroughly analyzed and studied in several interesting ways (see e.g., [5] and references therein), showing how they may lead to unusual phenomena with potential applications. In particular, the »complementary « pairing of materials with oppositely-signed constitutive parameters has been shown to provide a resonance phenomenon at the interface of the two media with interesting implications [5]. In particular, we have recently shown elsewhere how such resonances at the interface of a grounded bilayer may be employed to compact the transverse size of open waveguides supporting leaky-wave modes. We have proposed the use of these bilayers as leaky-wave radiators [6], and as covers to enhance the wave transmission through a small aperture in a perfectly conducting screen [7].

Leaky-wave antenna applications have a long tradition in the microwave community (see e.g., [9-10] and more recently [11-13]). Their use has been proposed in several fields, due to the peculiar radiation properties of these supported natural modes, which may be appealing in different applications.
The intrinsic limitation in their transverse dimension of being comparable with the operating wavelength in order to radiate efficiently is an example of the »diffraction limit « in these types of structured and may potentially be overcome by employing grounded metamaterial bilayers, as we have theoretically shown in [6]. Related to these discoveries, an extensive analysis of some leaky-wave properties of grounded metamaterial single layers has been presented in [11] and some metamaterial leaky-wave antenna setups have been proposed in [12-13] using planar 2-D metamaterials.

In a different context, some of these leaky-wave setups may be utilized as thin sub-wavelength covers to enhance the wave transmission through a sub-wavelength aperture over a perfectly conducting screen, as shown in [7]. Indeed exploiting the leaky-wave radiation of these bilayers as covers, when properly designed, may enhance the wave »reception « of the aperture and the transmission of power through the hole, together with the directivity towards a preferred direction where an observer may be placed. This setup may have several interesting potential applications such as spatially filtering electromagnetic radiation, photolithography, near-field microscopy, or microwave imaging. This phenomenon is related to the enhancement of wave transmission through small apertures exploiting the leaky-wave supported by proper corrugations over a metallic screen [14], as originally proposed by Oliner, Jackson and their coworkers [15], and to the concept applied to metamaterial single 
layers by our group in [16]. The extension of this concept to metamaterial bilayers, as reported in [7], may potentially reduce the overall thickness of the required covers to sub-wavelength dimensions, together with increasing the overall performance of the setup, thanks to the proper excitation of the anomalous interface resonance, characteristics of these bilayers. Both of these cited phenomena would rely on the excitation of these resonant leaky modes in sub-wavelength structures and here we review thoroughly their analyses giving some insights into the analogies between the two applications.

\section{LEAKY-WAVE DISPERSION PROPERTIES OF SUB-WAVELENGTH GROUNDED METAMATERIAL BILAYERS}

Consider a grounded bilayer made of two infinitely-extent, juxtaposed slabs of thicknesses $d_{1}$ and $d_{2}$ with permittivity and permeability $\varepsilon_{1}, \mu_{1}$ and $\varepsilon_{2}$, $\mu_{2}$ at the operating frequency $\omega$, backed by a perfectly conducting ground plane (see Figure 1). It is possible to show that the leaky modes supported by this structure satisfy the following dispersion relations, depending on the polarization [5-6]:

$$
\begin{array}{cl}
\mathrm{TE}: & f_{1}^{T E} f_{2}^{T E}-\frac{k_{y 2}^{2}}{\mu_{2}^{2}}=-j \frac{k_{y 0}}{\mu_{0}}\left(f_{1}^{T E}+f_{2}^{T E}\right) \\
\mathrm{TM}: \quad \frac{k_{y 2}^{2}}{\varepsilon_{2}^{2}}\left(f_{1}^{T M}+f_{2}^{T M}\right)=-j \frac{k_{y 0}}{\mu_{0}}\left(f_{1}^{T M} f_{2}^{T M}-\frac{k_{y 2}^{2}}{\varepsilon_{2}^{2}}\right) \\
\text { with } \quad f_{i}^{T E}=\frac{k_{y i} \cot \left(k_{y i} d_{i}\right)}{\mu_{i}}, \\
f_{i}^{T M}=\frac{k_{y i} \tan \left(k_{y i} d_{i}\right)}{\varepsilon_{i}}
\end{array}
$$

and

$$
k_{y i}=\sqrt{\omega^{2} \varepsilon_{i} \mu_{i}-\beta^{2}} \quad(i=0,1,2) .
$$

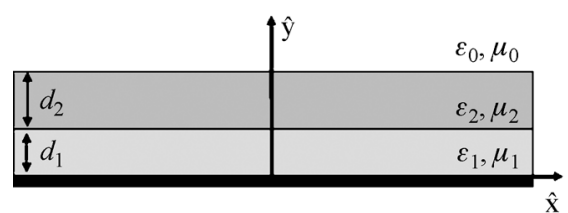

Fig. 1 Geometry of the problem: a grounded bilayer

The improper leaky modes or proper complex modes supported by this structure correspond to the solutions of (1) with complex values for $\beta$ and $\operatorname{Re}[\beta]<k_{0}=\omega \sqrt{\varepsilon_{0} \mu_{0}}$. Moreover, for the applications we foresee, such solutions should have a low value of $\operatorname{Im}[\beta]$, corresponding to highly directive radiating modes.
When sub-wavelength bilayers are considered, i.e., $\max \left[\left|k_{y 1}\right| d_{1},\left|k_{y 2}\right| d_{2}\right] \ll 1$, such solutions may exist when »conjugate« bilayers [5] are utilized, i.e., when negative-permittivity (ENG), negative-permeability (MNG) [5], and/or double-negative (DNG) media are paired together or with some dielectrics. Moreover, such solutions are supported when the bilayers satisfy one of the following further conditions, depending on the polarization:

$$
\begin{array}{ll}
\text { TE : } & \max \left(\left|\mu_{1}\right|,\left|\mu_{2}\right|\right) \ll \mu_{0} \\
\text { TM : } & \max \left(\left|\varepsilon_{1}\right|,\left|\varepsilon_{2}\right|\right) \ll \varepsilon_{0}
\end{array} .
$$

As noticed in [6-7], such conditions are related to the physical considerations that on the one hand the layers should act as a »lens « for the radiation coming from a given source, and this is obtained with low values of permittivities or permeabilities, similar to the effect obtained in [16], and that their transverse size should be considerably reduced, and this is obtained exploiting the interface resonance present at the interface between dielectrics, ENG MNG and DNG media [9]. Under these limits Eqs. (1) are simplified into

$$
\begin{aligned}
& \mathrm{TE}: \quad d_{1}, d_{2} \simeq \frac{\mu_{2}}{k_{y 2}^{2} \mu_{1}} \\
& \mathrm{TM}: \quad d_{1}, d_{2} \simeq \frac{\varepsilon_{1}}{k_{y 1}^{2} \varepsilon_{2}}
\end{aligned}
$$

These equations constitute design formulas for the two slab thicknesses once the materials and the desired beam angle for the leaky-wave radiation $\theta=\sin ^{-1}\left(\beta / k_{0}\right)$ are chosen.

\section{LEAKY-WAVE RADIATORS}

It is straightforward to apply the previous theory in the design of compact leaky-wave radiators with anomalous properties. In this case, a source should be included in the analysis, which, depending on the polarization, may be an electric or a magnetic dipole suitably placed near or inside the bilayer. In [6] we have considered the design of sub-wavelength highly directive leaky-wave radiators employing the anomalous properties of the previous formulas. For instance, Figure 2 shows the radiation pattern of an antenna, designed following this analysis, to radiate at $55^{\circ}$ from the normal. The bilayer has $\varepsilon_{1}=\varepsilon_{2}=\varepsilon_{0}, \mu_{1}=0.06 \mu_{0} . \mu_{2}=-10^{-3} \mu_{0}, d_{1}=$ $=\lambda_{0} / 50, d_{2}=\lambda_{0} / 35.5$, for a total thickness of less than $\lambda_{0} / 20$. The calculated directivity for this subwavelength radiator is $22 \mathrm{~dB}$. This radiator works in the TE polarization, which, due to the »quasi-static « nature of the resonance at the bilayer interface, is in most part affected by the material permeabilities, rather than their permittivities. 


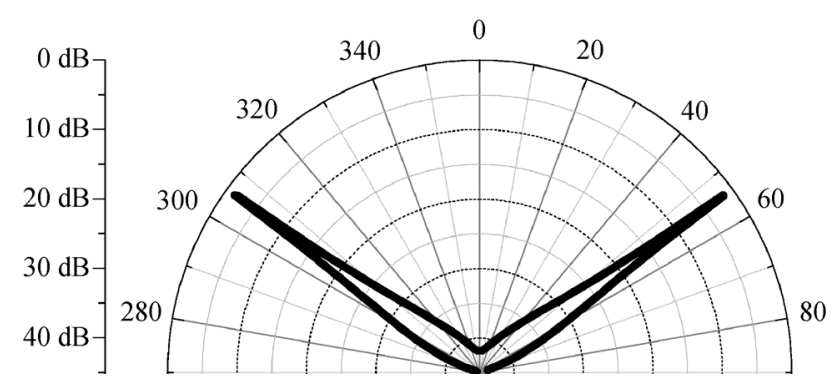

Fig. 2 From [6]. Radiation pattern of the bilayer of Figure 1 with $\varepsilon_{1}=\varepsilon_{2}=\varepsilon_{0}, \mu_{1}=0.06 \mu_{0} . \mu_{2}=-10^{-3} \mu_{0}, d_{1}=\lambda_{0} / 50, d_{2}=\lambda_{0} / 35.5$, de signed following the previous section to radiate at $55^{\circ}$ in the azimuthal plane

As shown in [6], a TM leaky-wave antenna, optimized following the previous analysis, would be less robust, since grounded low-permittivity layers would enhance the reactive fields near the source. We have designed one such case to radiate at broadside and the radiation pattern is plotted in Figure 3, where we have considered an electric source placed at the interface between the two metamaterial slabs. In this case, the geometrical parameters are: $\mu_{1}=\mu_{2}=\mu_{0}, \varepsilon_{1}=-0.025 \varepsilon_{0}, \varepsilon_{2}=-10^{-4} \varepsilon_{0}, d_{1}=\lambda_{0} / 27$, $d_{2}=\lambda_{0} / 30$. The materials employed are both ENG, and the resonance happens among them and the free space. The calculated directivity for this configuration is $17.85 \mathrm{~dB}$.

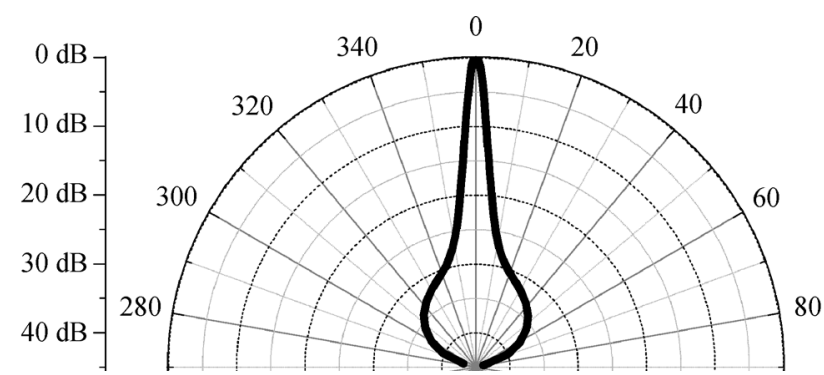

Fig. 3 From [6]. Radiation pattern of the bilayer of Figure 1 with $\mu_{1}=\mu_{2}=\mu_{0}, \varepsilon_{1}=-0.025 \varepsilon_{0} . \varepsilon_{2}=-10^{-4} \varepsilon_{0}, d_{1}=\lambda_{0} / 27, d_{2}=\lambda_{0} / 30$, de signed following the second part of Equation (4) to radiate at broadside

This second example underlines how it is possible, due to the absence of periodic corrugations in the present design, to avoid the usual cut-off present at broadside in common leaky-wave radiators. This novel technique, therefore, may allow the possibility of scanning the angle of radiation continuously from endfire to backfire, as also happens in other different metamaterial leaky-wave antenna setups [12-13] in planar technology.

We have also noticed that the required materials in these designs, following (2), have very low (close to zero) permittivity or permeability. This requisite does not usually necessitate strong resonances in- side the metamaterials, but it may be fulfilled in regions of weak resonances of the inclusions. Therefore, we can expect relatively low loss (compared with the loss at the resonance) in these metamaterial layers at the operating frequencies.

We have studied the sensitivity of the previous and other similar designs to real-life constraints, such as the presence of material losses, tolerance in the available geometrical and constitutive parameters of the materials, finiteness of the structure in the transverse direction and finiteness of the metal conductivity. As expected, these limitations have been theoretically shown to affect in part the »ideal« results, but a reasonable design can be shown to be robust to slight changes in the design parameters. An extensive analysis of this application will be published in the near future.

\section{ENHANCEMENT OF WAVE TRANSMISSION THROUGH SUB-WAVELENGTH APERTURES IN PEC SCREENS}

The same design formulas derived in Section 3 may be applied to another different setup, for the design of sub-wavelength covers for an aperture over a perfectly conducting screen, in order to enhance the wave transmission through the hole. The mechanism underlying this phenomenon is analogous to the one for the leaky-wave antennas described in the previous section: the cover at the entrance face of the hole would act as a receiving antenna, concentrating the field on the aperture, whereas the cover at the exit face would enhance the tunneling of power, together with the directivity of the beam towards an observer placed in the far-field, basically acting as a transmitting antenna.

Attention, however, should be paid to the position of the aperture, which acts as a receiver for the entrance cover and as a source for the exit layer.

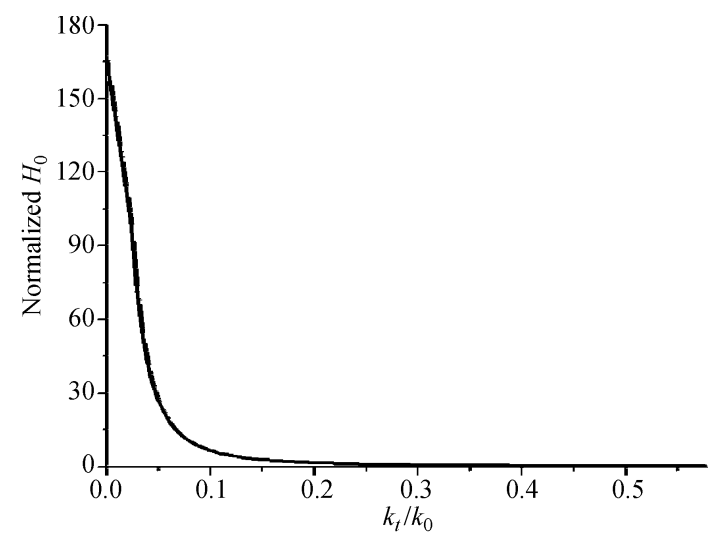

Fig. 4 From [7]. Magnetic field enhancement on the hole varying the angle of incidence of an incident plane wave, normalized to the case without the cover 

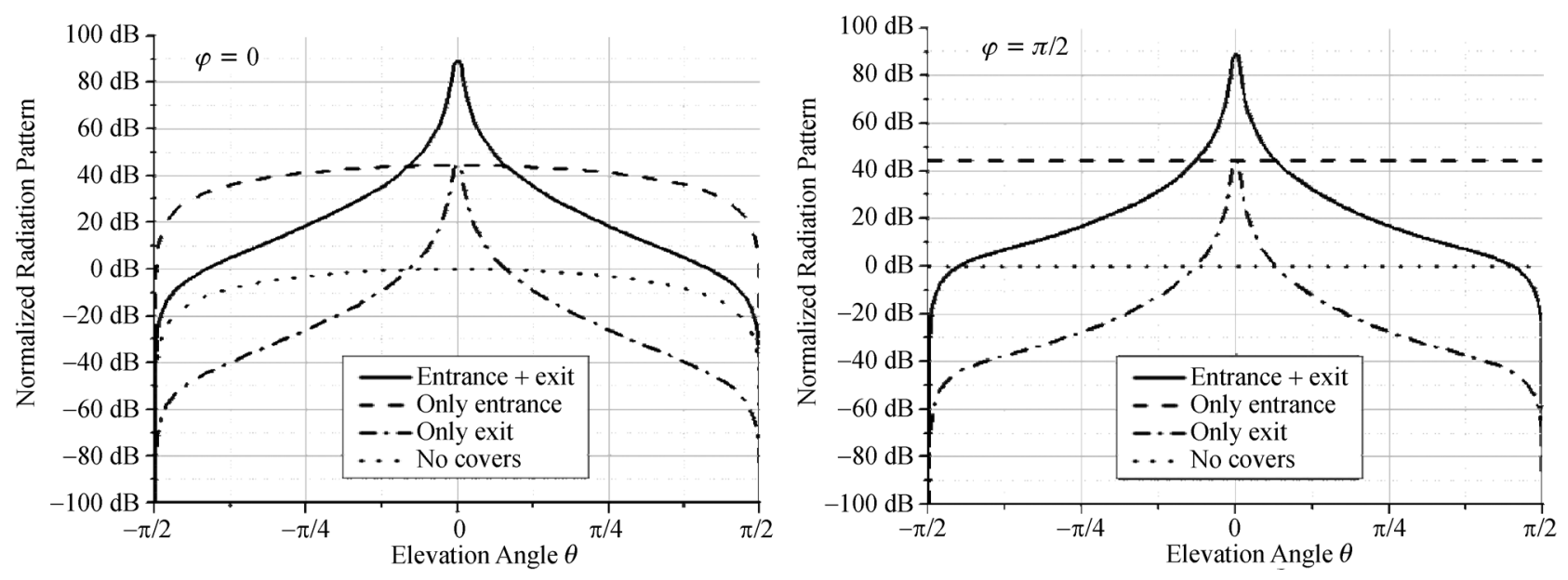

Fig. 5 From [7]. Radiation patterns in two planes $\phi=0^{\circ}$ and $\phi=90^{\circ}$, normalized to the pattern with no covers

Being an equivalent magnetic source, we should follow the formula corresponding to the TM polarization in Section 3 to achieve the proper enhancement. Applying the previous formulas, we have designed in [7] an optimized bilayer for having a small thickness and a high gain. This leads to the material parameters: $\varepsilon_{1}=9.957 \varepsilon_{0}, \mu_{1}=0.034 \mu_{0}, \varepsilon_{2}=5.747 \varepsilon_{0}$, $\mu_{2}=-0.283 \mu_{0}$, with a total cover thickness $d_{1}+d_{2} \simeq$ $\simeq 0,72 \lambda_{0}$. Such a cover has been designed to work at broadside, as theoretically confirmed by Figure 4 , which shows the magnetic field enhancement on the hole, normalized to the case without the cover, in terms of the transverse wave number of an incident plane wave. The cover at the exit side would act in a reciprocal way, similar to the corrugation effect in the exit side as mentioned by Oliner, Jackson and their group [15], enhancing further the wave throughput and reshaping the beam in order to radiate most part of the power towards the observer. The radiation patterns in the cases with no cover, a cover at the entrance or at the exit face, and with both covers have been calculated and are reported in Figure 5.

As evident from the figures, the total power enhancement in transmission using the identical covers on the two sides is almost $10^{\circ}$. Clearly, this is an idealized situation, in which realistic values for the material losses or the finiteness of the cover have not been considered. However, also in this problem we have considered realistic limitations to this setup in our simulations, and have theoretically obtained promising results.

\section{CONCLUSIONS}

Sub-wavelength grounded bilayers made of metamaterials may be conveniently designed to support leaky-waves. Here we have shown how the recently proposed applications of this setup to design of compact sub-wavelength leaky-wave radiators and for enhancing the wave transmission through apertures over conducting screens rely on the same principle and may be promptly designed following similar considerations. The source in the radiator and the aperture on the screen play a similar role, and the design should carefully consider their position. Anomalous radiation properties and physical phenomena may be shown by applying these considerations to the two setups presented here.

\section{ACKNOWLEDGEMENTS}

Andrea Alù, has been partially supported by the 2004 SUMMA Graduate Fellowship in Advanced Electromagnetics.

\section{REFERENCES}

[1] J. B. Pendry, A. J. Holden, D. J. Robbins, W. J. Stewart, Low-Frequency Plasmons in Thin Wire Structures. Journal of Physics: Condensed Matter, vol. 10, pp. 4785-4809, 1998.

[2] J. B. Pendry, A. J. Holden, D. J. Robbins, W. J. Stewart, Magnetism from Conductors and Enhanced Nonlinear Phenomena. IEEE Trans. on Microwave Theory and Techniques, vol. 47, no. 11, pp. 2075-2081, Nov. 1999.

[3] R. A. Shelby, D. R. Smith, S. Schultz, Experimental Verification of a Negative Index of Refraction. Science, vol. 292, no. 5514, pp. 77-79, April 6, 2001.

[4] R. W. Ziolkowski, E. Heyman, Wave Propagation in Media Having Negative Permittivity and Permeability. Physical Review E, vol. 64, no. 5, 056625, 2001.

[5] A. Alù, N. Engheta, Pairing an Epsilon-Negative Slab with a Mu-Negative Slab: Resonance, Tunneling and Transparency. IEEE Trans. on Antennas and Prop., Special issue on Metamaterials, pp. 2558-2571, October 2003.

[6] A. Alù, F. Bilotti, N. Engheta, L. Vegni, Compact Leaky-Wave Components Using Metamaterials. To appear in Proceedings of the IEEE MTT-S 2005 International Microwave Symposium (IMS'05), Long Beach, California, USA, June 12-17, 2005. 
[7] A. Alù, N. Engheta, L. Vegni, Metamaterial Bilayers for Enhancement of Wave Transmission through a Small Hole in a Flat Perfectly Conducting Screen. In Proceedings of 2004 IEEE Antennas and Propagation Society (AP-S) International Symposium, Monterey, CA, USA, vol. 3, pp. 3163-3166, June 20-26, 2004.

[8] A. Alù, N. Engheta, Guided Modes in a Waveguide Filled with a Pair of Single-Negative (SNG), Double-Negative (DNG), and/or Double-Positive (DPS) Layers, IEEE Trans. on Microwave Theory and Techniques, vol. MTT-52, no. 1, pp. 199-210, January 2004.

[9] A. Hessel, General Characteristics of Traveling-Wave Antennas. In R. E. Collin, F. J. Zucker, Antenna Theory, McGraw-Hill ed., pp. 151-258, 1969.

[10] A. A. Oliner, Leaky Waves in Electromagnetic Phenomena. Proc. 1962 Symp. Electromag. Theory Antennas, E. M. Jordan, ed., Pergamon Press, Oxford, England, pp. 837-856, 1963.

[11] P. Baccarelli, et al., Effects of Leaky-Wave Propagation in Metamaterial Grounded Slabs Excited by a Dipole Source. IEEE Trans. Microw. Theory \& Tech., vol. 53, pp. 32-44, Jan. 2005.
[12] A. Grbic, G. V. Eleftheriades, Leaky CPW-Based Slot Antenna Arrays for Millimeter-Wave Applications. IEEE Trans. Antenn. Propag., vol. 50, no. 11, pp. 1494-1504, Nov. 2002.

[13] L. Liu, T. Itoh, Dominant Mode Leaky-Wave Antenna with Backfire-to-Endfire Scanning Capability. Electronics Letters, vol. 38, no. 23, pp. 1414-1416, Nov. 7, 2002.

[14] D. E. Grupp, H. J. Lezec, T. Thio, T. W. Ebbsen, Beyond the Bethe Limit: Tunable Enhanced Light Transmission through a Single Sub-Wavelength Aperture, Advanced Materials, vol. 11, no. 10, pp. 860-862, 1999.

[15] A. A. Oliner, D. R. Jackson, Leaky Surface-Plasmon Theory for Dramatically Enhanced Transmission through a Sub-Wavelength Aperture, Part I: Basic Features, Proc. IEEE Ant. Prop. Symp., vol. 2, pp. 1091-1094, 2003; D. R. Jackson, T. Zhao, J. T. Williams, A. A. Oliner, Part II: Leaky Wave Antenna Model. Ibid., pp. 1095-1098, 2003.

[16] A. Alù, F. Bilotti, N. Engheta, L. Vegni, How Metamaterials May Significantly Affect the Wave Transmission through Sub-Wavelength Hole in a Flat Perfectly Conducting Screen. In Proc. IEE Seminar on Metamaterials for Microwave and (Sub) millimetre Wave Applications, London, UK, Nov. 24 2003, pp. 111-116.

Dvoslojni planarni metamaterijali s uzemljenom ravninom koji podržavaju cureće elektromagnetske valove principi i primjene. U članku je dana analiza dvoslojnih planarnih metamaterijala s uzemljenom ravninom koji podržavaju cureće elektromagnetske valove. Nedavno predložene primjene ovakvih metamaterijala obuhvaćaju kompaktne antene s curećim valom i tanke planarne prekrivne strukture za povećanje efikasnosti prijenosa elektromagnetske energije kroz vrlo male otvore (otvori čije su dimenzije mnogo manje od valne duljine) u zaslonima načinjenim od idealnih vodiča. Takvi dvoslojni metamaterijali podržavaju pojavu rezonancije na sučelju materijala s komplementarnim dielektričnim (ili magnetskim) svojstvima kao i efekt fokusiranja kod materijala s malim vrijednostima realnog dijela permitivnosti i/ili permeabilnosti. Koristeći ove neuobičajne elektromagnetske pojave moguće je konstruirati otvorenu višeslojnu strukturu za vođenje elektromagnetskog vala čija je debljina mnogo manja od valne duljine. U članku su analizirana glavna svojstva neuobičajnih elektromagnetskih modova s curećim valom $\mathrm{i}$ istražena povezanost fizikalnih temelja dviju predloženih primjena.

Ključne riječi: metamaterijali, cureći elektromagnetski valovi

\title{
AUTHORS' ADDRESSES
}

\author{
Andrea Alù $(1,2)$ \\ Filiberto Bilotti ${ }^{(1)}$ \\ Prof. Nader Engheta $(2)$ \\ Prof. Lucio Vegni $(1)$
}

(1) University of Roma Tre, Via della Vasca Navale, 84 - Roma, RM 00165, Italy e-mail: alu@uniroma3.it bilotti@uniroma3.it vegni@uniroma3.it

(2) University of Pennsylvania 200 South 33rd Street, Philadelphia, PA 19104, U.S.A. e-mail: engheta@ee.upenn.edu 